\title{
Outcome of Patients With Philadelphia Chromosome- Positive Chronic Myelogenous Leukemia Post-Imatinib Mesylate Failure
}

\author{
Hagop Kantarjian, MD ${ }^{1}$ \\ Susan $\mathbf{0}^{\prime}$ Brien, MD ${ }^{1}$ \\ Moshe Talpaz, $\mathrm{MD}^{2}$ \\ Gautam Borthakur, MD ${ }^{1}$ \\ Farhad Ravandi, MD ${ }^{1}$ \\ Stefan Faderl, MD ${ }^{1}$ \\ Srdan Verstovsek, MD ${ }^{1}$ \\ Mary Beth Rios, RN ${ }^{1}$ \\ Jianqin Shan, $\mathrm{PhD}^{1}$ \\ Francis Giles, ${ }^{1}{ }^{1}$ \\ Jorge Cortes, MD ${ }^{1}$ \\ ${ }^{1}$ Department of Leukemia, University of Texas \\ M. D. Anderson Cancer Center, Houston, Texas. \\ ${ }^{2}$ Division of Hematology/Oncology, University of \\ Michigan Health System, Ann Arbor, Michigan.
}

Address for reprints: Hagop M. Kantarjian, MD, Department of Leukemia, Box 428, University of Texas M. D. Anderson Cancer Center, 1515 Holcombe Blvd., Houston, TX 77030; Fax: (713) 792-2031; E-mail: hkantarj@mdanderson.org

Received October 31, 2006; revision received December 21, 2006; accepted January 3, 2007.
BACKGROUND. The prognosis of patients with chronic myelogenous leukemia (CML) after failure of imatinib mesylate therapy is not well documented.

METHODS. The outcome of 420 patients with CML post-imatinib failure (resistance-recurrence in 374 ; toxicities in 46 ) were reviewed in relation to survival, overall, and by different therapies.

RESULTS. The estimated 3-year survival rates were $72 \%$ in 88 patients who progressed in chronic phase, $30 \%$ in 130 patients who progressed in accelerated phase, $7 \%$ in 156 patients who progressed in blastic phase, and $75 \%$ in 37 patients in chronic phase with imatinib intolerance. Survival in chronic phase was better when subsequent therapy was nilotinib or dasatinib vs allogeneic stem cell transplant vs others (estimated 2 -year survival rates $100 \%$ vs $72 \%$ vs $67 \% ; P=.01$ ), but not in accelerated-blastic phase.

CONCLUSIONS. Prognosis post-imatinib failure in chronic phase is reasonable; it is poor if the CML phase post-imatinib failure is accelerated or blastic. Cancer 2007;109:1556-60. () 2007 American Cancer Society.

KEYWORDS: imatinib mesylate failure, chronic myelogenous leukemia, prognosis.

$\mathbf{T}$ he introduction of imatinib mesylate into the treatment of patients with Philadelphia chromosome $(\mathrm{Ph})$-positive chronic myelogenous leukemia (CML) has changed their prognosis drastically. In newly diagnosed CML, imatinib therapy is associated with an estimated 5 -year survival rate of $90 \% .^{1-3}$ The annual resistance rate to imatinib has been about $4 \%$ in the first 4 years. Prognosis in CML post-imatinib failure is reported to be poor, but there are no literature data pertaining to survival, particularly relating to the phase during which patients progress, and during which subsequent treatments such as allogeneic stem cell transplant (SCT) or the new-generation tyrosine kinase inhibitors are used. In this regard, we report the results from our institution.

\section{MATERIALS AND METHODS}

\section{Study Group}

All patients with a diagnosis of CML who received imatinib therapy since 1999 were analyzed. Patients had been treated on imatinib protocols after informed consent was obtained according to institutional guidelines. ${ }^{4-7}$ Patients who were taken off study were analyzed for the reason imatinib was discontinued, their characteristics including the CML phase for which they received imatinib, and the phase that they were in at the time imatinib was discontinued. Sub- 
TABLE 1

Characteristics of Patients Postimatinib Failure

\begin{tabular}{lllll}
\hline Parameter & Category & Resistance-recurrence & Toxicity & Total \\
\hline Total & & 374 & 46 & 420 \\
Age $(\mathrm{y})$ & Median & 54 & 60 & 54 \\
& No. $(\%) \geq 60$ & $134(36)$ & $23(50)$ & $157(37)$ \\
Duration of CML, mo & Median (range) & $53(2-293)$ & $36(2-167)$ & $51(2-293)$ \\
& No. $(\%) \geq 36$ & $233(62)$ & $22(48)$ & $255(61)$ \\
CML phase at imatinib & Chronic $\rightarrow$ chronic & 88 & 37 & \\
treatment and at relapse & Chronic $\rightarrow$ accelerated & 60 & - & \\
& Chronic $\rightarrow$ blastic & 41 & 8 & \\
& Accelerated $\rightarrow$ accelerated & 70 & - & \\
& Accelerated $\rightarrow$ blastic & 42 & 1 & \\
\hline
\end{tabular}

CML indicates chronic myelogenous leukemia.

sequent therapy was also coded, as to whether they underwent allogeneic SCT or received one of the novel bcr-abl inhibitors, dasatinib or nilotinib. ${ }^{8,9}$

\section{Statistical Considerations}

CML phase of disease and responses to imatinib, dasatinib, or nilotinib was described according to published criteria. $^{4-7}$ Differences among variables were calculated by the chi-square or Wilcoxon tests. Survival and remission duration curves were developed by the Kaplan-Meier method and compared by the log-rank test.

\section{RESULTS}

A total of 574 patients with CML after failure of imatinib regimens from 1999 until December 2005 were analyzed. These included 321 patients in chronic phase, 161 in accelerated phase (including clonal evolution only), and 92 in blastic phase. These patients had discontinued imatinib therapy for the following reasons: hematologic resistance or recurrence, 66 patients; cytogenetic resistance or recurrence, 63; progression to more advanced phases or in the same advanced phase, 245; imatinib toxicities, 46; choice of allogeneic SCT as a next best treatment option, 13; death while on imatinib therapy, 14; other reasons, 127 (outside follow-up, no follow-up available, noncompliance). The outcome of the latter 127 patients (86 in chronic phase, 33 in accelerated phase, 8 in blastic phase; $24 \%$ of total) could not be retrieved in detail in relation to subsequent therapies or survival. This may need to be considered in the interpretation of the data. The analysis next concentrated only on patients in whom imatinib therapy was discontinued for either clear-cut resistance or recurrence $(\mathrm{n}=374), \quad$ or for imatinib toxicities

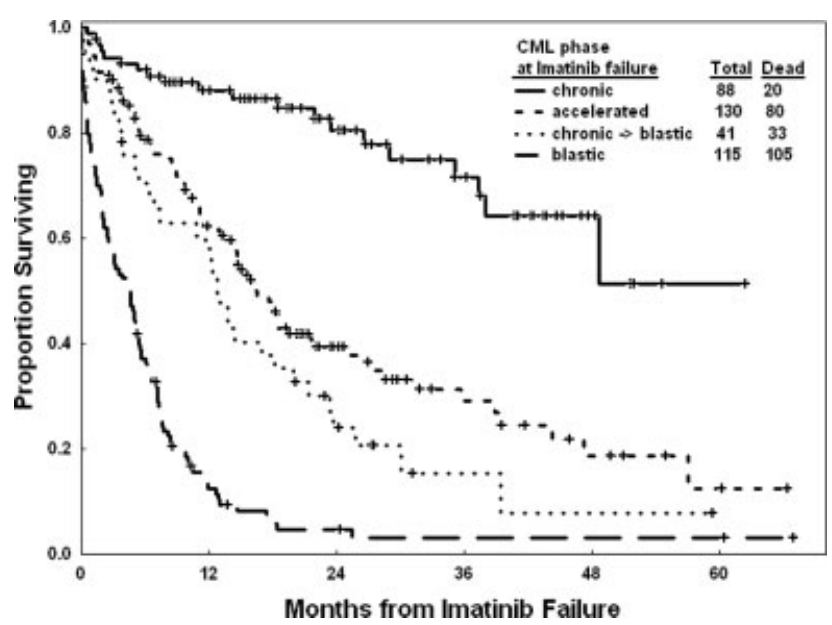

FIGURE 1. Survival of patients by chronic myelogenous leukemia (CML) phase at the time imatinib was started and at the time of imatinib failure due to resistance or recurrence.

( $n=46$ ), as previously defined. ${ }^{3-8}$ These 420 patients were then categorized by whether they received imatinib for 1) chronic phase and progressed while in chronic phase (chronic-chronic), in accelerated phase (chronic $\rightarrow$ accelerated), or in blastic phase (chronic $\rightarrow$ blastic); 2) for accelerated phase and progressed while still in accelerated phase (accelerated $\rightarrow$ accelerated) or in blastic phase (accelerated $\rightarrow$ blastic); or 3) for blastic phase. The characteristics of the study group are shown in Table 1 .

\section{Outcome Post-Imatinib Failure}

Among 88 patients post-imatinib resistance or recurrence in chronic phase the median survival was not reached; the estimated 3-year survival rate was $72 \%$ (Fig. 1). Survival was worse in 130 patients who remained or progressed into an accelerated phase 

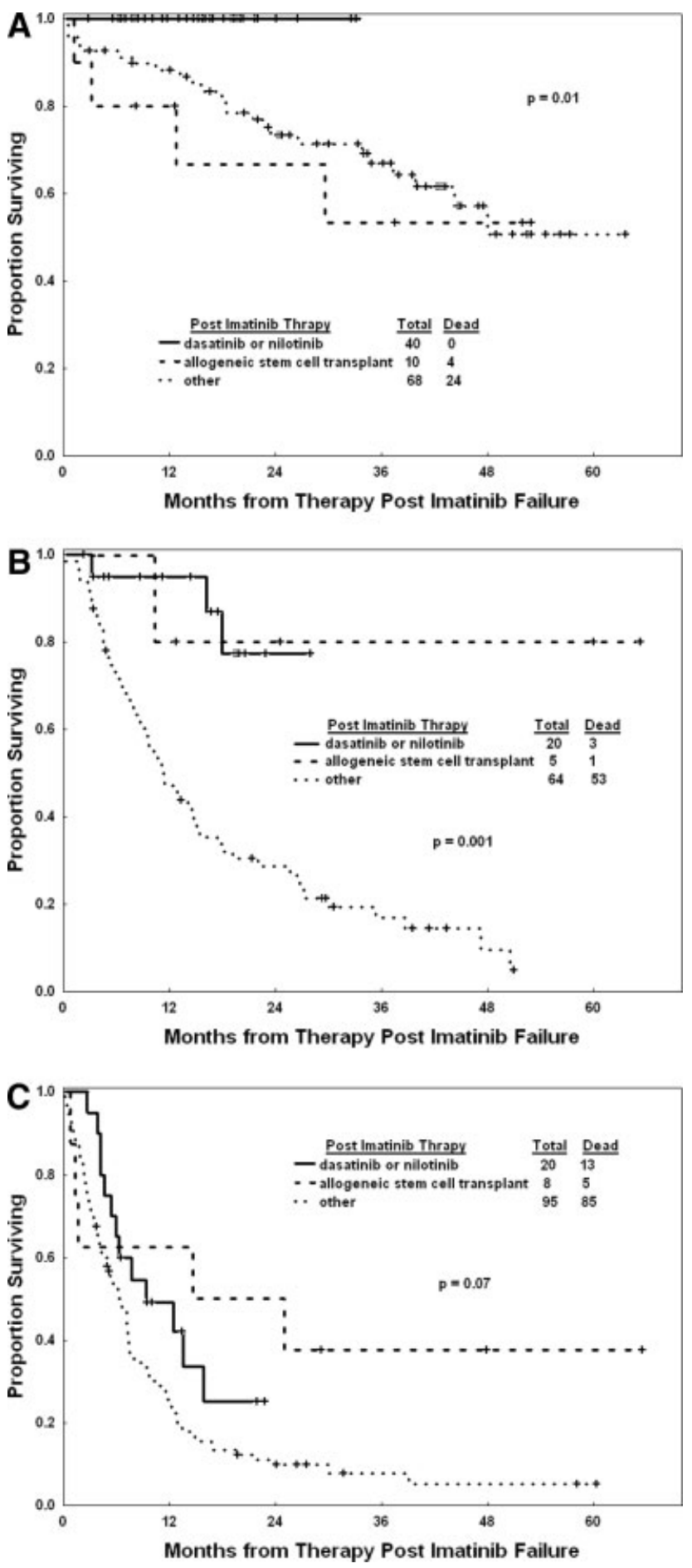

FIGURE 2. Survival (dated from start of post-imatinib therapy) of patients post-imatinib resistance-recurrence according to whether they subsequently underwent allogeneic stem cell transplant (SCT), dasatinib or nilotinib, or other regimens for chronic (A), accelerated (B), or blastic phases (C). (3-year survival 30\%; Fig. 1) and in 156 patients who remained or progressed into a blastic phase (3-year survival 7\%; Fig. 1). Survival for the 37 patients taken off imatinib because of side effects while in chronic phase was better: the estimated 3-year survival rate was $75 \%$.

Survival was similar among patients who had developed accelerated phase whether they started on imatinib in chronic or accelerated phase $(P=.51)$; these 2 categories were grouped together (Fig. 1). Survival in blastic phase was better in patients who had been in chronic phase on imatinib therapy compared with those who had been in accelerated-blastic phase (grouped together) $(P<.001$; Fig. 1$)$.

\section{Outcome by Postimatinib Therapy}

Outcome post-imatinib resistance-recurrence failure in chronic phase is shown in Figure 2A by whether the patients underwent allogeneic SCT $(n=10)$, dasatinib or nilotinib $(\mathrm{n}=40)$, or other therapies $(n=68)$. Figure 2B shows the outcome in accelerated phase by subsequent therapy with allogeneic SCT $(n=5)$, dasatinib or nilotinib $(n=20)$, or other therapies $(n=64)$. Figure $2 \mathrm{C}$ shows the survival in the 3 respective groups (number of patients 8,20 , and 95, respectively) who progressed in blastic phase.

\section{Prognostic Factors for Survival in Patients Postimatinib Failure While Still in Chronic Phase (Table 2)}

Because the prognosis in CML in transformation was poor, we next focused on the analysis of prognostic determinants of patients post-imatinib failure in chronic phase. By univariate analysis, adverse factors for survival were: the cause of imatinib failure (hematologic vs cytogenetic resistance-recurrence vs toxicity), splenomegaly, $100 \% \mathrm{Ph}$-positivity at start of therapy, anemia, leukocytosis, thrombocytosis, higher basophils and blasts percents. By multivariate analysis the independent poor prognostic factors selected were: splenomegaly $(P=.006)$; and hematologic failure $(P=.01)$. Patients with 0,1 , or 2 adverse factors had expected 2 -year survival rates of $91 \%, 75 \%$, and $0 \%$, respectively. Although patients receiving dasatinib-nilotinib appear to also do better than other subgroups (Fig. 2A; $P=.01$ ), therapy was not selected as an independent favorable factor for survival with the short follow-up time of this group; this may change with longer follow-up.

\section{DISCUSSION}

Whereas the prognosis of CML post-imatinib failure has been suspected to be poor, there are no pub- 
TABLE 2

Prognostic Factors for Survival Postimatinib Failure in Chronic Phase CML

\begin{tabular}{|c|c|c|c|c|c|}
\hline \multirow[b]{2}{*}{ Parameter } & \multirow[b]{2}{*}{ Category } & \multirow[b]{2}{*}{$\begin{array}{l}\text { No. } \\
\text { patients }\end{array}$} & \multicolumn{2}{|c|}{ Estimated survival } & \multirow[b]{2}{*}{$P$} \\
\hline & & & $\begin{array}{l}\text { Median, } \\
\text { mo }\end{array}$ & $\begin{array}{l}\% \text { at } \\
2 / 3 \text { years }\end{array}$ & \\
\hline \multirow[t]{2}{*}{ Age, y } & $\geq 60$ & 50 & NR & $78 / 78$ & .72 \\
\hline & $<60$ & 54 & NR & $85 / 66$ & \\
\hline \multirow[t]{3}{*}{ Sokal risk } & Low & 55 & NR & $88 / 72$ & .26 \\
\hline & Intermediate & 32 & 39.9 & $65 / 65$ & \\
\hline & High & 5 & NR & $60 / 60$ & \\
\hline \multirow[t]{3}{*}{ Duration of CML, y } & $\leq 1$ & 10 & NR & $73 / 73$ & .79 \\
\hline & $1-3$ & 26 & NR & $92 / 69$ & \\
\hline & $>3$ & 68 & NR & $78 / 75$ & \\
\hline \multirow[t]{3}{*}{ Imatinib failure } & Cytogenetic resistance-relapse & 33 & NR & $100 / 92$ & .003 \\
\hline & Hematologic resistance-relapse & 52 & 48 & $71 / 57$ & \\
\hline & Toxicity & 19 & NR & $82 / 82$ & \\
\hline \multirow[t]{3}{*}{ Therapy at failure } & Allogeneic SCT & 8 & 29.6 & $60 / 45$ & .01 \\
\hline & Dasatinib-nilotinib & 35 & NR & $100 / \mathrm{NA}$ & \\
\hline & Other* & 61 & NR & $77 / 70$ & \\
\hline \multirow[t]{2}{*}{ Hemoglobin. g/dL } & $<11$ & 28 & 37.3 & $61 / 54$ & .02 \\
\hline & $\geq 11$ & 68 & NR & $88 / 76$ & \\
\hline \multirow[t]{2}{*}{ WBC, $10^{9} / \mathrm{L}$} & $<10$ & 43 & NR & $93 / 78$ & .02 \\
\hline & $\geq 10$ & 53 & 39.9 & $68 / 63$ & \\
\hline \multirow[t]{2}{*}{$\%$ marrow blasts } & $<5$ & 86 & NR & $81 / 72$ & .19 \\
\hline & $\geq 5$ & 7 & 39.9 & $86 / 57$ & \\
\hline \multirow[t]{2}{*}{$\% \mathrm{Ph}+$ at start of postimatinib failure therapy } & $\leq 90$ & 27 & NR & $100 / 100$ & .003 \\
\hline & $>90$ & 68 & 48 & $73 / 60$ & \\
\hline \multirow[t]{2}{*}{ Splenomegaly } & No & 87 & NR & $83 / 75$ & .0004 \\
\hline & Yes & 6 & 17.9 & $31 / 0$ & \\
\hline \multirow[t]{2}{*}{$\%$ peripheral blasts } & 0 & 81 & NA & $83 / 70$ & .04 \\
\hline & Any & 15 & 37.3 & $63 / 63$ & \\
\hline \multirow[t]{2}{*}{ Platelets, $\times 10^{9} / \mathrm{L}$} & $\leq 400$ & 57 & $\mathrm{NR}$ & $92 / 79$ & .005 \\
\hline & $>400$ & 39 & 39.9 & $60 / 54$ & \\
\hline \multirow[t]{2}{*}{ Peripheral basophils \% } & $\leq 5$ & 83 & NR & $85 / 76$ & .06 \\
\hline & $>5$ & 13 & 23.4 & $48 / 32$ & \\
\hline \multirow[t]{2}{*}{ Marrow basophils \% } & $<5$ & 76 & NR & $87 / 79$ & .01 \\
\hline & $\geq 5$ & 17 & 34.7 & $64 / 49$ & \\
\hline \multirow[t]{3}{*}{ No. adverse factors by multivariate analysis } & 0 & 47 & NR & $91 / 91$ & $<.0001$ \\
\hline & 1 & 41 & 34.7 & $75 / 50$ & \\
\hline & 2 & 5 & 17.9 & $0 / 0$ & \\
\hline
\end{tabular}

lished data that estimate such a prognosis. This is important for patient-physician decision-making, as well as to establish individual patient expectations, and to assess the benefit of newer therapies. This analysis is the first to provide survival estimates post-imatinib failure. As expected, prognosis for patients who progress in accelerated or blastic phases is poor, the median survivals being 16 months and 5 months, respectively. Prognosis is better for patients who received dasatinib or nilotinib vs allogeneic SCT vs other therapies for chronic phase $(P=.01)$ but not in more advanced phases.
Surprisingly, patients with CML failure on imatinib in chronic phase still have a relatively good prognosis, with an estimated 3-year survival rate of $72 \%$. Of interest, the 46 patients with imatinib failure because of toxicities also had an estimated 3-year survival rate of $75 \%$ (expected to be better). This may be due to the short follow-up time. Not unexpectedly, patients with imatinib toxicity or cytogenetic resistance or recurrence have a better prognosis than those with hematologic resistance or recurrence. Patients treated in recent studies with newer tyrosine kinase inhibitors appear to also have a better prog- 
nosis. A multivariate analysis identified 2 simple adverse prognostic factors that could estimate patient prognosis by presence or absence of 0,1 , or 2 adverse factors: the estimated 2-year survival rates were $91 \%, 75 \%$, and $0 \%$, respectively. This observation could serve to advise patients of their prognosis and treatment options, as well as to evaluate the benefit of newer therapies in the context of imatinib failure.

Prognosis of patients post-imatinib failure who are treated with the new tyrosine kinase inhibitors or with allogeneic SCT may be strongly associated with the degree of cytogenetic or molecular response to these particular therapies. This analysis focused on survival post-imatinib failure, the original intent of the study. Outcome by cytogenetic-molecular response will be reported in the context of these individual therapies.

\section{REFERENCES}

1. O'Brien SG, Guilhot F, Larson RA, et al., for the IRIS Investigators. Imatinib compared with interferon and low-dose cytarabine for newly diagnosed chronic-phase chronic myeloid leukemia. N Engl J Med. 2003;348:994-1004.

2. Kantarjian H, Talpaz M, O'Brien S, et al. Survival benefit with imatinib mesylate versus interferon alpha-based regi- mens in newly diagnosed chronic phase chronic myelogenous leukemia. Blood. 2006;108:1835-1840.

3. Roy L, Guilhot J, Krahnke T, et al. Survival advantage from imatinib compared with the combination interferon plus cytarabine in chronic-phase chronic myelogenous leukemia: historical comparison between two phase 3 trials. Blood. 2006;108:1478-1484.

4. Kantarjian H, Cortes J, O'Brien S, et al. Long-term survival benefit and improved complete cytogenetic and molecular response rates with imatinib mesylate in Philadelphia chromosome-positive, chronic-phase chronic myeloid leukemia after failure of interferon-alpha. Blood. 2004;104:1979-1988.

5. Kantarjian H, Talpaz M, O’Brien S, et al. High-dose imatinib mesylate therapy in newly diagnosed Philadelphia chromosome-positive chronic phase chronic myeloid leukemia. Blood. 2004;103:2873-2878.

6. Kantarjian H, Talpaz M, O’Brien S, et al. Survival benefit with imatinib mesylate therapy in the accelerated phase of chronic myelogenous leukemia - comparison with historical experience. Cancer. 2005;103:2099-2108.

7. Talpaz M, Silver R, Druker B, et al. Imatinib induces durable hematologic and cytogenetic responses in patients with accelerated phase chronic myeloid leukemia: results of a phase 2 study. Blood. 2002;99:1928-1937.

8. Talpaz M, Shah NP, Kantarjian H, et al. Dasatinib in imatinib-resistant Philadelphia chromosome-positive leukemias. N Engl J Med. 2531-2541;354:24.

9. Kantarjian H, Giles F, Wunderle L, et al. Nilotinib in imatinib-resistant CML and Philadelphia chromosome-positive ALL. N Engl J Med. 2006;354:2542-2541. 